Environmental Assessment

Strategies

in support of the

Nonproliferation Alternative

Systems Assessment Program

(NASAP)

R. M. Emery

M. L. Warner

H. R. Meyer

C. A. Little

J. E. Till

October 1977

Prepared for the

U.S. Department of Energy

under Contract EY-76-C-06-1830 


\title{
ENVIRONMENTAL ASSESSMENT STRATEGIES \\ in support of the \\ NONPROLIFERATION ALTERNATIVE SYSTEMS \\ ASSESSMENT PROGRAM \\ (NASAP)
}

\begin{abstract}
R. M. Emery and M. L. Warner
Battelle, Pacific Northwest Laboratories

Richland, Washington 99352

and

H. R. Meyer, C. A. Little, and U. E. Ti11

Oak Ridge National Laboratory

Oak Ridge, Tennessee 37830
\end{abstract}

October 1977

\section{Resource Personne1}

PNL

W. J. Bair

E. A. Bondietti

J. E. Baliou

J. A. Carpenter, Jr.

W. I. Enderl in

W. Davis, Jr.

R. F. Foster

D. E. Dunning

J. C. Fox

C. T. Garten

T. R. Garland

F. 0. Hoffman

D. L. Hesse1

S. V. Kaye

T. J. Kabele

R. E. Moore

S. Marks

P. S. Rohwer

W. L. Templeton

C. C. Travis

R. C. Thompson, ur.

P. J. Walsh

C. M. Unruh

J. P. Witherspoon

B. E. Vaughan 
CONTENTS

Page

1 INTRODUCTION . . . . . . . . . . . . . . . . . . . 1

1.1 Purpose of the Report . . . . . . . . . . . . . . . 1

1.2 Overview of Alternative Fuel Cycles . . . . . . . . . . 2

2 KEY ENVIRONMENTAL AND HEALTH (E\&H) ISSUES. . . . . . . . . . . . . . 6

2.1 Identification of Potential Issues. . . . . . . . . . . . 7

2.1.1 Mining and Milling............... . 7

2.1.1.1 Radiological.............. . 7

2.1.1.2 Chemical-Toxicological. . . . . . . . 8

2.1.1.3 Thermal............... 8

2.1.1.4 Resource Use. . . . . . . . . . . 8

2.1.2 Conversion, Enrichment and Fuel Fabrication. . . . . 9

2.1.2.1 Radiological. . . . . . . . . . . . 9 9

2.1.2.2 Chemical-Toxicological. . . . . . . . 10

2.1.2.3 Thermal............... 10

2.1.2.4 Resource Use. ............. 10

2.1.3 Reactor Operation. .............. 10

2.1.3.1 Radiological.............. . 10

2.1.3.2 Chemical-Toxicological. . . . . . . . 11

2.1.3.3 Thermal................ . 11

2.1.3.4 Resource Use. . . . . . . . . . . . . 11

2.1.4 Fuel Reprocessing. ................ . 11

2.1.4.1 Radiological. ............... . 11

2.1.4.2 Chemical-Toxicological. . . . . . . . 13

2.1.4.3 Thermal............... 14

2.1.4.4 Resource Use. . . . . . . . . . . . 14

2.1.5 Solid Waste Management . . . . . . . . . . . 14

2.1.5.1 Radiological............. . 14

2.1.5.2 Chemical-Toxicological. ......... 15

2.1.5.3 Thermal.............. 15

2.1.5.4 Resource Use............... 15 
2.1.6 Transportation............. . . 16

2.1.6.1 Radiological. ......... 16

2.1.6.2 Chemical-Toxicological. ...... 16

2.1 .6 .3 Therma $1 . . . . . .16$

2.1.6.4 Resource Use. . . . . . . . . . 16

2.2 Summary of Key Issues . . . . . . . . . . . . 16

2.2.1 Mining and Milling............. 16

2.2.2 Conversion, Enrichment and Fuel Fabrication. . . . 17

2.2.3 Fuel Reprocessing. . . . . . . . . . 17

2.2.4 Solid Waste Management ........... . 17

2.2.5 Transportation............. . 17

3 ENVIRONMENTAL ASSESSMENT STRATEGIES. . . . . . . . 18

3.1 Categories of Assessment Options. . . . . . . . 18

3.2 Criteria for Evaluation . . . . . . . . . . 18

3.3 Analysis of Assessment Options........... 20

3.3.1 Grouping of Fuel Cycles. ........... 20

3.3.2 Identification of Environmental and Health Issues. . 23

3.3.3 Expression of Source Terms . . . . . . . . 25

3.3.4 Specification of Development Scenarios . . . . . 27

3.3.5 Comparison of fuel Cycles. ........... 29

3.4 Conclusions ....................... 31

4 SUMMARY AND RECOMMENDATIONS. . . . . . . . . . . . . . . 32

4.1 Key E\&H Issues. . . . . . . . . . . . . . 32

4.2 Environmental Assessment Strategies ......... . 33

5 REFERENCES .................... 34 


\section{ENVIRONMENTAL ASSESSMENT STRATEGIES \\ in support of the \\ NONPROLIFERATION ALTERNATIVE SYSTEMS \\ ASSESSMENT PROGRAM (NASAP)}

1 INTRODUCTION

\subsection{Purpose of the Report}

The U.S. Department of Energy (DOE) is currently conducting a Nonproliferation Alternative Systems Assessment Program (NASAP) to identify nuclear fuel cycle options that pose inherently low risks of nuclear weapons proliferation while retaining the major benefits of nuclear energy. During FY 1978, the desirability and effectiveness of al ternative nuclear fuel cycles will be examined in terms of the cycles' proliferation risk, technical feasibility, economic feasibility, and potential environmental and health effects. Final recommendations based on these several assessments may be made late in FY 1978.

Carefully planned, highly efficient research strategies will be required to complete the necessary assessments within the anticipated time frame. The purpose of this report is to identify and evaluate alternative strategies for organizing the environmental and health (E\&H) effects assessment. Following a brief review of the range of aiternative nuclear fuel cycles under consideration, the report consists of three major sections. A discussion of what presently appear to be the most significant environmental and health issues associated with alternative fuel cycles is presented in Section 2. Major choice points in developing an effective assessment strategy, and the range of options available at each, are identified and evaluated in Section 3. Section 4 summarizes conclusions and recommends courses of action for proceeding with the detailed NASA.P environmental assessment. 
In preparing this report, staff members of the Battelle, Pacific Northwest Laboratories and the Oak Ridge National Laboratory have been guided by three key understandings:

- The anticipated FY-78 environmental assessment effort will be highly condensed, perhaps six months in duration.

- The objective of the assessment effort is to allow comparison of alternative fuel cycles with respect to their most critical impacts without detailed analysis of other environmental impacts judged to be of lesser significance.

- An assessment of the international E\&H impacts of alternative fuel cycles is required.

In view of the limited information available at this time, the observations and recommendations made in this report should be considered preliminary and subject to review during the course of the actual assessment.

\subsection{Overview of Alternative Fuel Cycles}

Sixty-nine alternative fuel systems were chosen for initial investigation within the scope of NASAP. Three criteria were used in the selection process. First, a system was chosen if it appeared to be more favorable from a nonproliferation viewpoint than unrestricted plutonium recycie systems. All systems, therefore, must eschew the availability of nongamma-emitting, separated fissile material. Second, the candidate systems were also limited to those which appeared to utilize uranium at least as efficiently as the current light-water reactor (LWR) throwaway system. Third, the systems all were judged technically feasible and economically competitive with fossil fueled energy systems.

The selected fuel cycles fall into two basic categories: "oncethrough" or "throwaway" cycles in which recycling is not allowed and "constrained recycle" systems wherein recycling operations are restricted by various methods. 
Very briefiy, "once-through" systems include: optimized LWR designs, other existing reactor concepts, and modified reactors. Optimized LWRs are those in which design traits previously included in anticipation of reprocessing are removed to allow optimal fuel utilization. Other existing reactor concepts include high temperature gas-cooled reactor (HTGR) and heavy-water reactor (HWR) designs. Modified reactor concepts, such as the spectral shift reactor, the tandem fuel cycle, accelerator-driven reactors, and fusion hybrid reactors are also included as al ternatives.

"Constrained recycle" systems include: partial recycle, coprocessed recycle, spiked recycle, and variations of the energy center concept. Partial recycle includes retrieval of uranium and thorium and disposal of plutonium. Coprocessing would leave gamma-emitting residual fission products in the U/Pu output stream, requiring additional remote chemical separation to convert the material to a weapons-usable form. Spiked recycle is similar to coprocessing except that the output stream is separated into $U$ and Pu. The energy center concept would minimize the risks of proliferation oriented theft by co-locating reactors, enrichment plants, and reprocessing to minimize transportation and to facilitate plant security.

Table 1.2, List of Reference and Candidate Alternative Systems, from the Draft NASAP preliminary program report (U.S. ERDA 1977), is included to clarify this brief discussion. The following narrative comments on the organization of the table.

Ten groups of fuel systems are included. The first five groups center around five reactor types; namely, light-water reactors (LWR), gascooled reactors (GCR), heavy-water reactors (HWR), liquid metal fast breeder reactors (LMFBR), and gas-cooled fast reactors (GCFR). Each of these five is further subdivided by considering several recycle strategies for both the U-Pu and Th-U cycles. Additionally, the HWR group includes several recycle options for both the LWR/HWR tandem cycle and the spectral shift reactors. 


\section{TABLE 1.2 List of Reference and Candidate $\Lambda 1$ ternative Systems}

\begin{tabular}{|c|c|c|}
\hline \multirow[t]{7}{*}{ Group } & 1.1 & LWA (U.Pu) \\
\hline & 1.11 & Standard recycle (reference) \\
\hline & 112 & Spiked recycle \\
\hline & 113 & Caprocessed recycie \\
\hline & $1 .: 4$ & Uranium recycle, Pu throwaway \\
\hline & 1.15 & Once through-oxide fuel \\
\hline & $: 1.6$ & Once through-metallic fuel \\
\hline \multirow[t]{3}{*}{ Group } & 1.2 & LWA (Th.U) \\
\hline & 12.1 & Full recvele \\
\hline & 12.2 & Partial recycle. Pu throwaway \\
\hline \multirow[t]{8}{*}{ Group } & 2.1 & Gas-Cooled resctors (U.Pu cycle) \\
\hline & 2.1 .1 & Standard recycle in HTGR (reference) \\
\hline & 2.1 .2 & Spikeo recycie in HTGR \\
\hline & 2.13 & Coprocessed recycle in HTGR \\
\hline & 2.14 & Partual recycle. Pu throwaway in $\mathrm{HTGR}$ \\
\hline & 2.15 & HTGR once through-oxide fuel \\
\hline & 2.1 .6 & GCR once through-metallic fuel \\
\hline & 2.17 & Standard recycle in AGr (reference) \\
\hline \multirow[t]{5}{*}{ Group } & 2.2 & HTGR (Th-U eycle) \\
\hline & 2.2 .1 & Fult recycle \\
\hline & 2.2 .2 & Partial recycie \\
\hline & 2.2 .3 & HEU-Th iCarbidel HTGR full recyeie ireferencel \\
\hline & 2.2 .4 & HEU.Th in pebble bed gas reactor with fult recycle (reference) \\
\hline \multirow[t]{4}{*}{ Group } & 3.1 & HWR (U-Pu Cycle) \\
\hline & 3.1 .1 & Standard fecycle \\
\hline & 3.1 .2 & Spiked recvele \\
\hline & 3.13 & Once through-oxide fuel \\
\hline \multirow[t]{3}{*}{ Group } & 3.2 & HWA (Th-U Cycle) \\
\hline & 3.2 .1 & Full recycle \\
\hline & 3.2 .2 & Partzal cecycle. Pu throwaway \\
\hline \multirow[t]{3}{*}{ Group } & 3.3 & LWR HWR Tandem Cycle \\
\hline & 331 & Tandern cycle witn reconstituted fuet \\
\hline & 332 & Tandern cycle without recanstituted fuei \\
\hline \multirow[t]{3}{*}{ Group } & 3.4 & Spectral shift reectors \\
\hline & 3.41 & Once-through uranium cycle \\
\hline & 3.4 .2 & Th-U full recycle \\
\hline \multirow[t]{4}{*}{ Group } & 4.1 & LMFBA (U.Pu ercle) \\
\hline & 4.1.1 & LMFBR LWR standard recycle (reference) \\
\hline & 4.12 & LMFBA / LWR coprocessed racycle - oxide fuel \\
\hline & 4.13 & LMFBR / LWR coprocessed recvcle - carbide fugl \\
\hline \multirow[t]{4}{*}{ Group } & 4.2 & LMFBA (Th-U Cyclo) \\
\hline & 42.1 & U-PU-Th Full Recycle LMFBR/LWR \\
\hline & 4.2 .2 & U.233/U.238/TnLMFBR / LWR U recycle, PU throwaway \\
\hline & 4.2 .3 & U. 233 /Th LMFBR / LWR Fuil Recycle \\
\hline \multirow[t]{4}{*}{ Group } & 5.1 & GCFR (U-Pu Cycto) \\
\hline & 5.1 .1 & GCFA/LWR standard racycie (retorence) \\
\hline & 5.12 & GCFA/LWR coprocessed recycle - oxide fuel \\
\hline & 5.13 & GCFR LWR coprocessed recrcle - carbide fuel \\
\hline
\end{tabular}

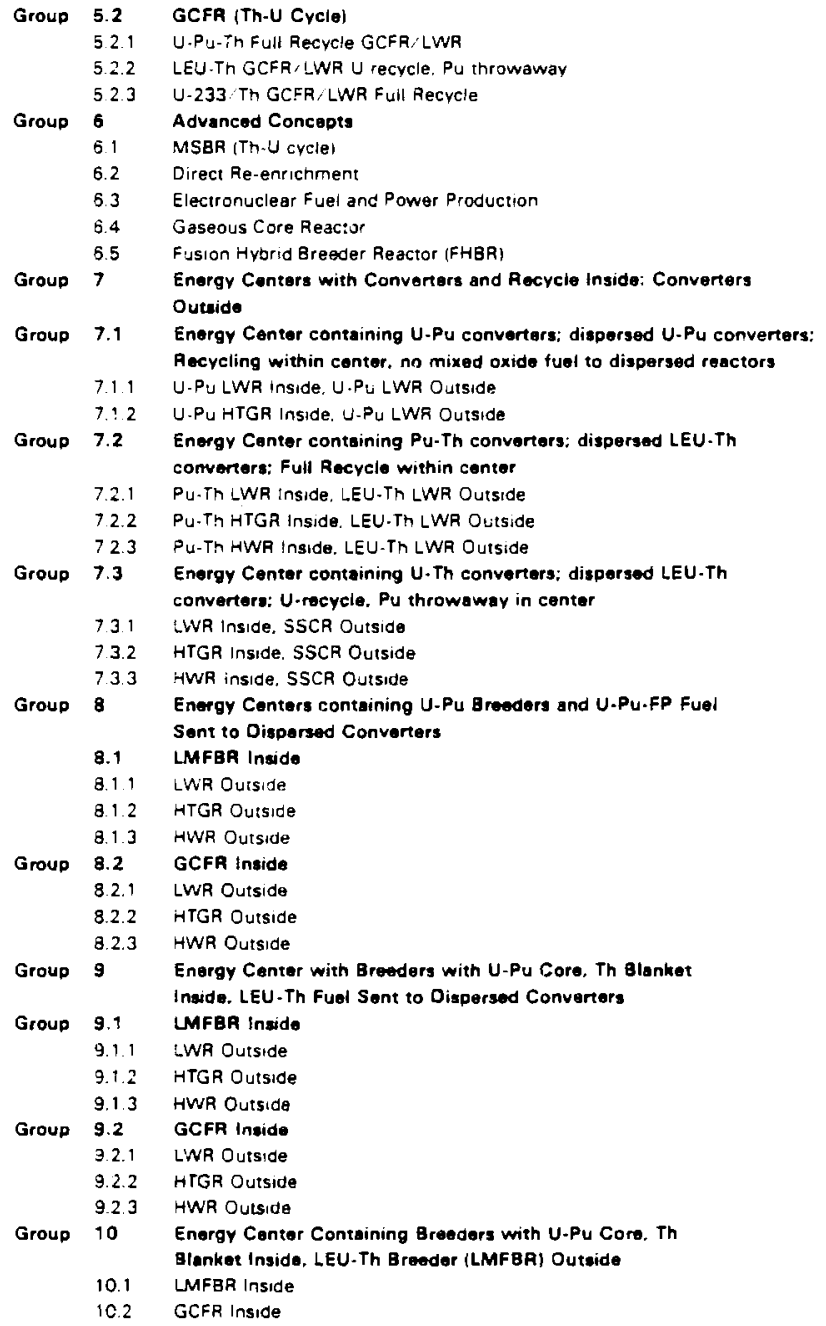

Formerly Table 3-1. of U S.ERDA. 1977 Nonproliferation Alternative Systems Assessinent Program - Preliminary Program Plan (Draft). Division of Nuclear Research and Applications, Nuclear Energy Assessments, May 1977 
A sixth group of candidate systems is composed of five advanced concepts which fit neither the "once-through" or "constrained recycle" strategies, but which do exhibit attractive nonproliferation capabilities. The advanced concepts include the Th-U molten salt breeder reactor, a direct re-enrichment option, the electronuclear production of fuel and power, the gaseous core reactor, and the fission/fusion hybrid reactor.

The seventh through tenth groups of candidate cycles are groups of energy center concepts. These concepts are basically locational and institutional combinations of the preceding fuel systems.

This 1 ist of alternative fuel cycle candidates will later be reduced to a minimum by combining similar systems into groups or by selecting representatives from a group. The primary criterion for this selection process will primarily be the nonproliferation potential of the system considered. 


\section{KEY ENVIRONMENTAL AND HEALTH (E\&H) ISSUES}

In preparation of this report, we consider two general fuel cycle types. The first involves the uranium/plutonium (U/Pu) concept where the $\mathrm{Pu}$ is made unavailable for weapons development, while the second involves the use of thorium and ${ }^{233_{\mathrm{U}}}\left(\mathrm{Th} /{ }^{233_{\mathrm{U}}} \mathrm{)}\right.$, el iminating proliferative quantities of Pu from the cycle. Numerous fuel cycles have been proposed or developed on the basis of one or the other of these systems.

An E\&H issue is defined as any aspect of a fuel cycle that is capable of creating a significant risk to man or the environment. The critical nature of an E\&H issue (i.e., a "key issue") is a matter of the seriousness of the hazard. For this report, key E\&H issues are considered to be those that could significantly influence the international acceptability of a NASAP fuel cycle.

A number of E\&H issues are common to both types of cycles, but some are specific to the cycle type or to a unit process within a certain step in a given fuel cycle. Potential E\&H issues that must be considered for all nonproliferative alternatives will be identified. In these discussions, references are not commonly made to specific fuel cycles, which have not yet been selected from the field of alternatives. Therefore identification of potential issues will be in a generic sense. This discussion addresses the issues in terms of general population/occupational and routine; accidental scenarios. The modes of potential impact that are considered include radiological, chemical-toxicological, thermal, and resource use (physical disturbance). Whenever possible regulatory requirements and international implications for certain key E\&H issues are discussed. Also addressed are issues of potential but undetermined importance. Following the identification of potential issues in each step of the fuel cycles, judgment will be rendered as to those issues which appear to be most important. 


\subsection{Identification of Potential Issues}

In this discussion, the fuel cycle is segmented into mining and militing; conversion, enrichment and fuel fabrication; reactor operation; fuel reprocessing; solid waste management; and transportation.

\subsubsection{Mining and Milling}

\subsubsection{Radiological:}

The potential exists within this fuel cycle step for large differences in E\&H hazard levels among the various fuel cycle cptions. The mining and milling of both uranium and thorium release radioactive materials to the environment via aqueous effluents and gaseous emissions. These mining and milling operations also result in potential occupational risks, e.g., lung cancer in uranium miners. Larger quantities of radioactive materials are expected to be released into the atmosphere through the mining and milling of thorium than for uranium. Of particular importance are the release of ${ }^{232} \mathrm{Th}$ and decay products including ${ }^{220} \mathrm{Rn}$. Dose rates obtained around thorium mining and milling operations are potentially higher than those around uranium operations.

Thorium mining requirements are strongly dependent on fuel cycle characteristics. Although thorium is also obtainable as a by-product from Canadian uranium mining, monazite sands are currently mined for titanium with $\mathrm{ThO}_{2}$ as a by-product. Presumably, mining of these resources (with associated E\&H consequences) would continue regardless of thorium utilization in a nuclear fuel cycle.

The potential for release of large quantitites of radon or thoron gas exists for both $U$ and Th mining. Available data and assessment methodologies appear sufficient to adequately quantify this hazard in terms of population doses, thus providing the basis for establishing control technology levels. 
The occupational hazard associated with uranium mining is established. Similar lung cancer hazard levels might be expected to be associated with underground thorium mining, al though the requirement for underground mining may not soon exist. Presumably, world dependence upon a Th cycle would eventually lead to underground Th mining. The hazard of accidentrelated radiological release from either $U$ or Th mining operations is seen to be of little consequence.

\subsubsection{Chemical-Toxicological:}

Occupational health, public health and environmental impact are identified as issues. U.S. ERDA (1976) conceptualizes a mine-mill complex for comparing the impact of mining and milling thorium with that of uranium. This document identifies liquid waste discharge and land use to be the essential differences between the two operations in terms of E\&H issues. During thorium recovery, dredging of monazite sands often releases large quantities of humates, lowering the pH of aqueous effluents. This requires treatment of waste effluents with caustic soda to normalize the $\mathrm{pH}$ and with alum to flocculate and settle the humate and suspended fines. Uranium mining and milling do not present this problem, but do require the settling of suspended fines. In addition, acid leach and solvent extraction processes that produce ammonium diuranate could have associated toxicological problems.

\subsubsection{Thermal:}

The release of thermal energy does not appear to raise any health or environmental issues related to uranium or thorium mining and milling.

\subsubsection{Resource Use:}

Adequacy of the supply of uranium for the LWR "throwaway" cycle remains open to question. In no available scenario does land-use or related impacts of uranium mining appear to be significant when compared to the 
requirements of most non-nuclear fuel cycles. Thorium mining, involving a more concentrated ore of greater availability, may present still smaller land-use-related impacts. Nevertheless, the following issues are raised for consideration.

Depending on the source of monazite sands used for extraction of thorium, there exists the possibility that significant habitat disruption could occur in the Atlantic coastal region of the southeast. This potential disruption exists because monazite sands are deposited in coastal regions where sensitive aquatic and terrestrial communities may be impacted.

From an international standpoint, neither $U$ nor Th mineral deposits in Europe appear to be available in sufficient quantity for sustained use, al though further prospecting of the European continent may reveal additional sources. Conversion to a Th cycle is not expected to result in significantly reduced dependence of the European community on U.S., Canadian, Russian, Brazilian and Australian sources. The availability of a larger world resource base is an economic encouragement for Th-based vs. uranium-based cycles.

The cumulative land committment of the worldwide nuclear industry is a matter worth considering. Differing worldwide distributions of uranium vs. thorium may be important since the location of the resources may be as critical an issue as the quantity required. Similarly, the differing habitats affected by uranium vs. thorium mining is an issue since the type of habitat disturbed might be as important as the magnitude of disturbance.

\subsubsection{Conversion, Enrichment and Fuel Fabrication}

\subsubsection{Radiological:}

A major issue is potential exposure to gamma and neutron radiation. This potential varies greatly among proposed fuel systems. Safeguardsrelated fuel spiking procedures will impose increased gamma hazards to 
workers and to the general public. Depending upon fuel type and the extent of recycle envisioned, neutron dose to workers is a potential issue. To meet current and proposed standards may impose a heavy economic penalty for certain fuel cycles. Issues also exist regarding the potential for release of uranium salts in conversion plant effluents and the release of $U F_{6}$ and volatiles such as ${ }^{99}$ Tc from the enrichment process. Alpha-contamination via transuranium elements may also constitute an E\&H hazard.

\subsubsection{Chemical-Toxicological:}

Conversion and enrichment processes involve toxic chemicals such as trichloroethylene and ammonium diuranate dust, and some proposed fuels involve use of toxic metals such as cadmium and nickel (Schneider et al., 1977). Thus, occupational health is a potential issue and recent OSHA standards could cause technical and economic problems.

\subsubsection{Therma1:}

Gaseous diffusion plants require input of large quantities of electrical power, with resultant large thermal releases. The use of gas centrifuge technology should reduce the energy requirements and associated thermal releases. Extent of enrichment is highly dependent upon the nature of the specific fuel cycle. Hence, possible environmental degradation associated with power consumption is an issue.

\subsubsection{Resource Use:}

No issues are identified, but fuel cycles to be assessed should be examined for possible exceptions.

\subsubsection{Reactor Operation}

\subsubsection{Radiological:}

Routine releases from the current generation of nuclear power plants are of very low magnitude, necessitating the use of sophisticated, 
integrative detection equipment merely to demonstrate the offsite distribution of particulate or liquid-borne radionuclides. Occupational and public health issues are associated with the possibility of accidental failure of containment systems. This potential hazard exists for al1 nuclear reactors. The relative potential for accidental release from al ternative fuel cycle reactors requires further analysis, and the likelihood exists that a specific reactor type (e.g., the low total reactivity "pebble bed" reactor) may show a significantly reduced possibility of accidental radionuclide release.

\subsubsection{Chemical-Toxicological:}

No fuel cycle-specific issues can be identified for currently considered reactor types.

\subsubsection{Thermal:}

Variations in thermal efficiency among reactor types under consideration lead to the potential for increased heat dissipation to atmospheric or aquatic heat sinks by the lower efficiency facilities. Resultant issues include thermal effects on aquatic ecosystems, and the potential for weather modification under certain conditions.

\subsubsection{Resource Use:}

No issues are identified with the possible exception of special requirements for specific cases, including variations in water requirements, total underground implacement of reactors, large areas for nuclear parks, etc.

\subsubsection{Fuel Reprocessing}

\subsubsection{Radiological:}

Some of the most significant differences between $\mathrm{Th} /{ }^{233} \mathrm{U}$ and $\mathrm{U} / \mathrm{Pu}$ fuel cycles are evident in the context of reprocessing. Continuous 
upgrading of entrapment methodology for radioactive pollutants has greatly decreased the potential for hazard from routine releases for reprocessing, refabrication and power reactor facilities (if well designed and operated). Liquid releases are no longer "designed into" such facilities (with minor exceptions), and solid wastes are expected to be transported routinely to a central, off-site storage or burial facility. Airborne releases, for which a body of complex dose estimation methodologies is maturing, are controlled via reliable filtration systems to very low levels. Only a few gaseous emissions, among them ${ }^{3} H,{ }^{14} \mathrm{C}$, ${ }^{85} \mathrm{Kr},{ }^{129} \mathrm{I}$ and ${ }^{131} \mathrm{I}$ remain as significant routine releases. Difficulties exist in estimating worldwide population doses from these gaseous emissions, and the potential for significant differences between fuei cycles in total quantity emitted (per unit electrical energy) requires that the NASAP analysis estimate such doses for a worldwide, equilibrated nuclear fuel cycle. While technology may provide an entrapment mechanism for ${ }^{3} \mathrm{H}$ and ${ }^{14} \mathrm{C}$, variations in cost between cycles toward provision of adequate control may be large.

Pechin et a1. (1975), Davis et a1. (1976), Roddy et al. (1976), and Finney et al. (1977) indicate few significant differences in terms of radiological impact between $U / P U$ and $T h / 233 U$ reprocessing of the volatile fission and activation products that may enter gaseous effluents. Production of ${ }^{129}$ I is similar in both fuel cycles. HTGR fuel elements contain increased ${ }^{14} \mathrm{C}$ and ${ }^{85} \mathrm{Kr}$ while LWR fuels generally contain increased amounts of ${ }^{3} \mathrm{H}$. Accidental releases of ${ }^{232} \mathrm{U},{ }^{233} \mathrm{U},{ }^{228} \mathrm{Th}$, and ${ }^{232} \mathrm{Th}$ and daughters are possible in the reprocessing of $\mathrm{Th} /{ }^{233} \mathrm{U}$ cycle fuel elements. Thus, the impacts on public health and the environment are potential issues requiring consideration of the transport of various radionuclides in the food chain, in air, etc. Requirements of current and proposed EPA standards for release of radionuclides to the environment may also be issues. 
Occupational health is also an issue in the handling of materials that emit gamma and neutron radiation. Reprocessed ${ }^{233} U$ will contain varying quantities of ${ }^{232} \mathrm{U}$ and its daughters, including high-energy gamma emitters requiring remote handling. Recycle of U/Pu fuel elements may not present this problem, but the possibility of hazardous levels of neutron exposure requires examination in this context.

The presence of alpha-emitting transuranics in the work environment may contribute to this issue. Neutron capture by Th results in greatly reduced transuranic production, when comparison is made to the neutron irradiation of uranium. The potential hazard associated with inhalation of the transuranics is great, and reduced production rates imply reduced hazard potential. A balancing of this $\mathrm{Th} /{ }^{233} \mathrm{U}$ cycle advantage against increased ${ }^{232} \mathrm{U},{ }^{233} \mathrm{U}$ and ${ }^{228} \mathrm{Th}$ production rates in thorium fuels is necessary. Fission product spectra for the two cycles also vary, and radiological hazard comparisons may be of significance in this context as well.

Difficulties associated with environmental activism/intervention are currently of great concern within the European community and may result in a nuclear construction moratorium. A careful analysis of the E\&H hazards associated with the $T h /{ }^{233} \mathrm{U}$ fuel cycle may thus provide information useful in the development of incentives toward conversion to a thorium cycle.

\subsubsection{Chemical-Toxicological:}

Fuel reprocessing involves numerous chemical agents. Whether substantial differences exist among all proposed fuel cycles remains to be determined. The potential issues are occupational exposures and related OSHA standards.

Al though the likelihood of substantial environmental release of chemical agents used in fuel reprocessing is small, possible issues are the requirements of the Toxic Substances Control Act and the air and water 
quality standards. Significance of and variation in chemical releases associated with reprocessing remain to be assessed in detail for the various fuel cycles.

Recent documents by Brenchley et al. (1977) and Killough and McKay (1976) provide valuable summaries of standards and limits for a number of radiological and nonradiological materials potentially released in $\mathrm{U} / \mathrm{Pu}$ fuel cycles, and are of great value for the forthcoming NASAP assessment.

\subsubsection{Thermal:}

No issues are expected since current fuel processing technologies do not release significant amounts of thermal energy to the environment.

\subsubsection{Resource Use:}

No issues have been identified.

\subsubsection{Solid Waste Management}

\subsubsection{Radiological:}

Technical resolution of problems associated with disposal of nuclear solid wastes is generally thought to be possible. Large-scale demonstration of these anticipated solutions is necessary. The level of occupational exposure to gamma- or neutron-radiation during waste solidification requires careful examination. The difficulties associated with siting a national waste repository in the U.S. are evident, and, due to the high population density, more severe siting difficulties exist within the European community. The routine or accidental release of fission products, transuranics, thorium, or uranium can lead to public and occupational health issues and to issues associated with contaminated terrestrial and aquatic ecosystems. Additional issues may be associated with current and planned standards for burial of waste on land or disposal in the ocean. It appears that solid wastes from a thorium-based cycle may be a lesser hazard than wastes 
from a uranium-based cycle. For example, Clarke et a1. (1975) reported radiological waste hazards of the $T h / 233 \mathrm{U}$ cycle to be as much as three orders of magnitude lower than corresponding U/Pu cycle wastes. Also, reduced transuranic production via the $T h /{ }^{233} \mathrm{U}$ cycle results in a significantly reduced alpha hazard.

Waste management hazards regarding long term storage of entrapped gaseous radionuclides requires analysis, because the potential exists for a gradual release of these radionuclides which could produce a significant dose to the population.

\subsubsection{Chemical-Toxicological:}

Methods being developed to convert radioactive wastes to forms suitable for disposal may involve the use of toxic chemicals. Thus, occupational exposures and OSHA standards are possible issues.

\subsubsection{Therma1:}

Waste heat output from solid waste management operations of $\mathrm{Th} / \mathrm{L}^{23} \mathrm{U}$ fuel cycles may be lower than that from U/Pu cycles because of the reduction of transuranic output via the $\mathrm{Th} /{ }^{233} \mathrm{U}$ cycle. Reduction in thermal output of the wastes may be of long-term importance, as salt-bed water movement is affected by thermal gradients, and, therefore, long-term integrity and mobility of buried wastes are also affected.

\subsubsection{Resource Use:}

Methods of waste disposal may require identification of potential resource use issues, such as the long-term commitment of land and subsurface areas. There may be major differences in the location and magnitude of these commitments among the NASAP options. 


\subsubsection{Transportation}

2.1.6.1 Radiological:

For all fuel cycles, transportation of various nuclear materials in all steps of the cycle has the potential for accidental release of radioactive materials to the environment. There are many potential acciaccidental situations, a11 of which are dependent on locations and transit routes for specific fuel cycle types. In nearly all of these, public health and, to lesser extent, occupational health are issues. Contamination of ecosystems is also a potential issue. The potential also exists for significantly increased general population gamma doses from the transportation of fuels containing $232 \mathrm{~J}$, or other safeguards-related gamma emitters.

\subsubsection{Chemical-Toxicological:}

No issues involving chemical toxicity have yet been identified.

\subsubsection{Therma 1:}

No issues have yet been identified.

\subsubsection{Resource Use:}

No issues have been identified.

\subsection{Summary of Key Issues}

While a relatively large number of potential issues have been identified for consideration within each stage of all fuel cycles, not a1 1 of these are of equal significance. Based on our best judgment we regard the following as being the key issues:

\subsubsection{Mining and Miliing}

- Radiological: - Health risk to miners and mil1 workers

- Health risk to public 
2.2.2 Conversion, Enrichment and Fuel Fabrication

- Radiological: - Occupational health risks

- Health risk to public

- Risk of contaminating environment

- Thermal: - Risk of environmental degradation associated with power consumption

\subsubsection{Fuel Reprocessing}

- Radiological: - Occupational health risk

- Health risk to public

- Risk of contaminating the environment

- Problems associated with compliance with EPA standards

\subsubsection{Solid Waste Management}

- Radiological: (associated with handling wastes from reprocessing plant vs. handling unreprocessed fuels)

- Occupational health risk

- Health risks to public

- Risk of contaminating the environment

\subsubsection{Transportation}

- Radiological: - Occupational health risk

- Heal th risk to public 


\section{ENVIRONMENTAL ASSESSMENT STRATEGIES}

\subsection{Categories of Assessment Options}

In developing a strategy for the environmental assessment of alternative fuel cycles, there are five key points at which important procedural options are apparent. This section describes these five categories of assessment options, evaluates the options within each category, and recommends preferred choices. The recommendations made should be viewed as preliminary only. At this writing, the specific fuel cycles to be examined have not yet been selected and other potentially critical information on the scope of the assessment effort is not available. The optional assessment strategies available and recommended choices should, therefore, be re-examined before the recommended strategy is implemented. The five categories of assessment options involve:

- Grouping of fuel cycles,

- Identification of environmental and health issues,

- Expression of source terms,

- Specification of development scenarios, and

- Comparison of fuel cycles.

As shown in Figure 3.1, these five categories of options can be viewed as generally independent, sequential choice points. By selecting an assessment option from each category, an environmental assessment strategy may be defined. Though the five categories of options are essentially independent, there are some instances in which the choice of an assessment option made in one category may influence the choice in another category, as described in Section 3.3, below.

\subsection{Criteria for Evaluation}

Assessment options within each category have been evaluated by use of the following eight criteria: 


\section{CATEGORIES OF OPTIONS}

1. GROUPING OF PUEL CYCLES
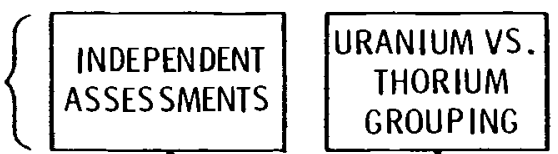

2. IDENTIFICATION OF E\&H ISSUES \{

3. EXPRESSION OF SOURCE TERMS \{

4. SPECIFICATION OF DEVELOPMENT SCENARIOS
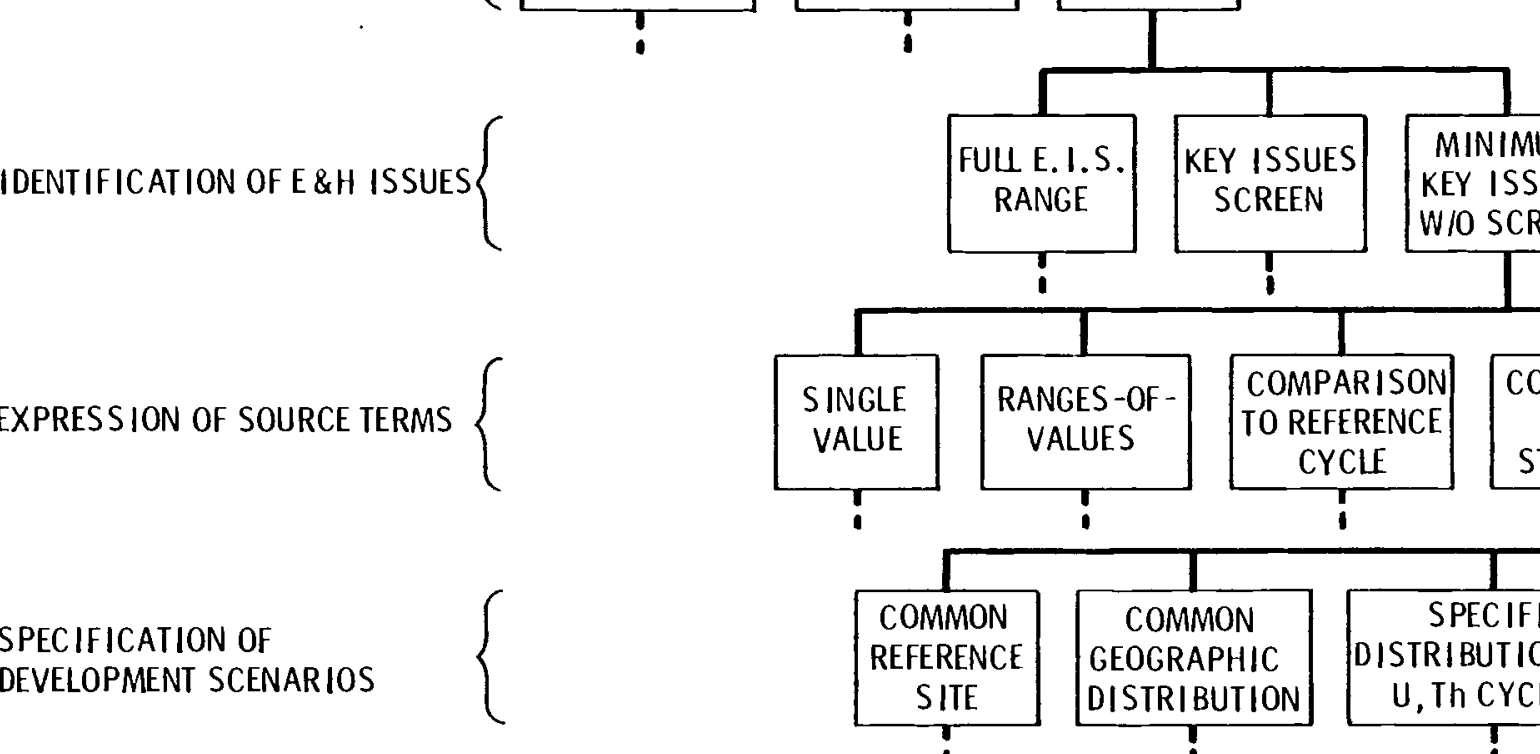

5. COMPARISON OF FUEL CYCLES \{

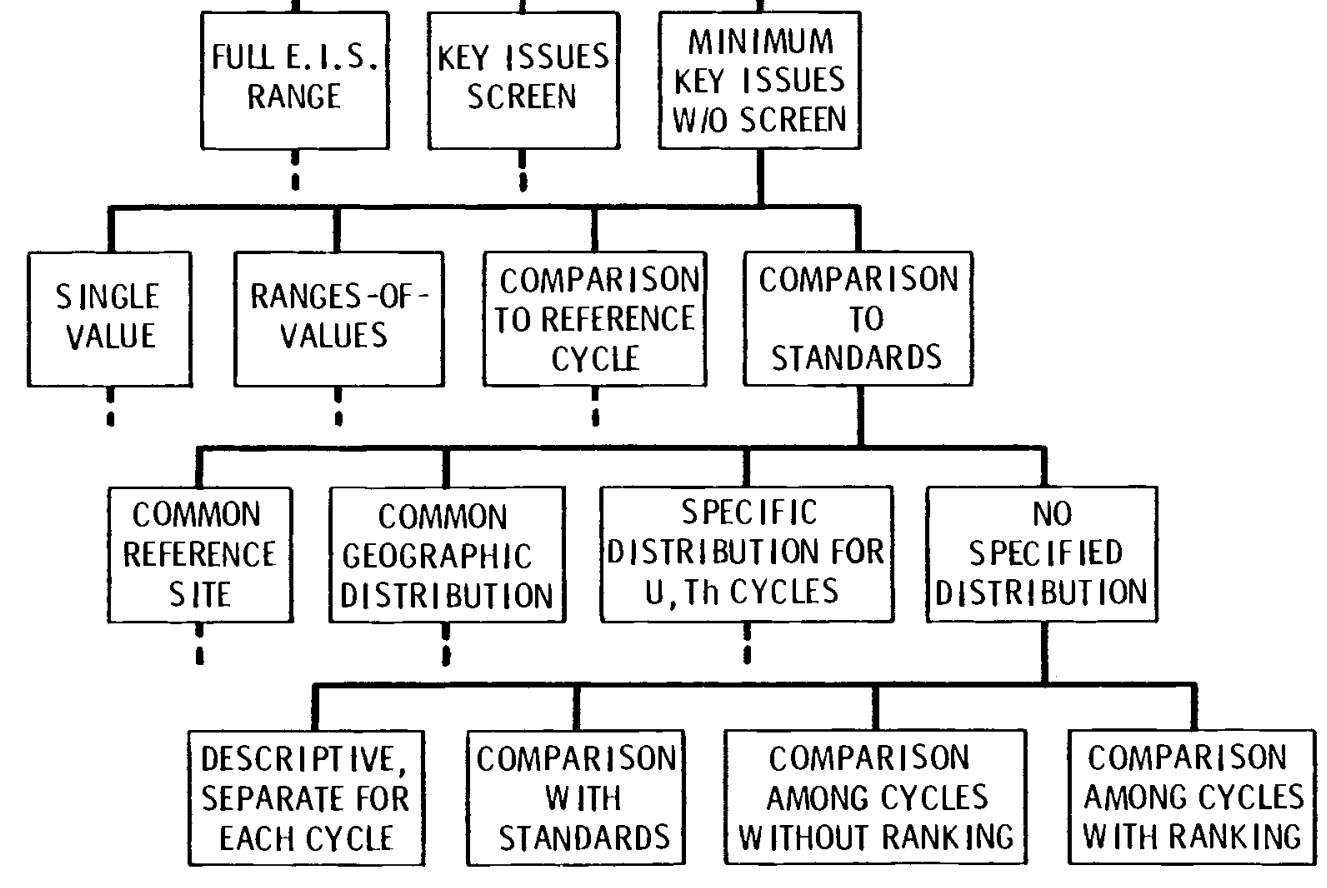

FIGURE 3.1 Options Available in Developing an Environmental Assessment Strategy 
- Inclusiveness

- Discrimination

- Budget and Time

- Cons istency

- Flexibility
- How likely is the method to pick up all environmental impacts which could affect decisions?

- How well will the method discriminate between environmental impacts of alternative fuel cycles?

- How likely is it that all necessary assessments will be completed within the anticipated budgetary and time constraints?

- How parallel in form and coverage will individual fuel cycle assessments be under the method?

- How adaptable will the method be to different laboratories and investigators, different fuel cycles, and changing needs of the program?

- Data Availability - Are data required by the method likely to be available within the expected time frame?

- Focus

- How well will the method minimize effort on less important issues and avoid redundancy?

- Carry-over

- How useful will assessments produced by the method be in future environmental analyses-including environmental impact statements?

Each criterion is an important consideration for some, but not all, categories of assessment options. The relationships between categories and criteria are shown in Table 3.1 .

\subsection{Analysis of Assessment Options}

\subsubsection{Grouping of Fuel Cycles}

Environmental assessments can be carried out independently on each alternative fuel cycle or on various combinations of fuel cycles or parts of cycles. The first major decision in selecting an overall assessment 
TABLE 3.1 Relationship Between Categories of Assessment Options and Evaluation Criteria

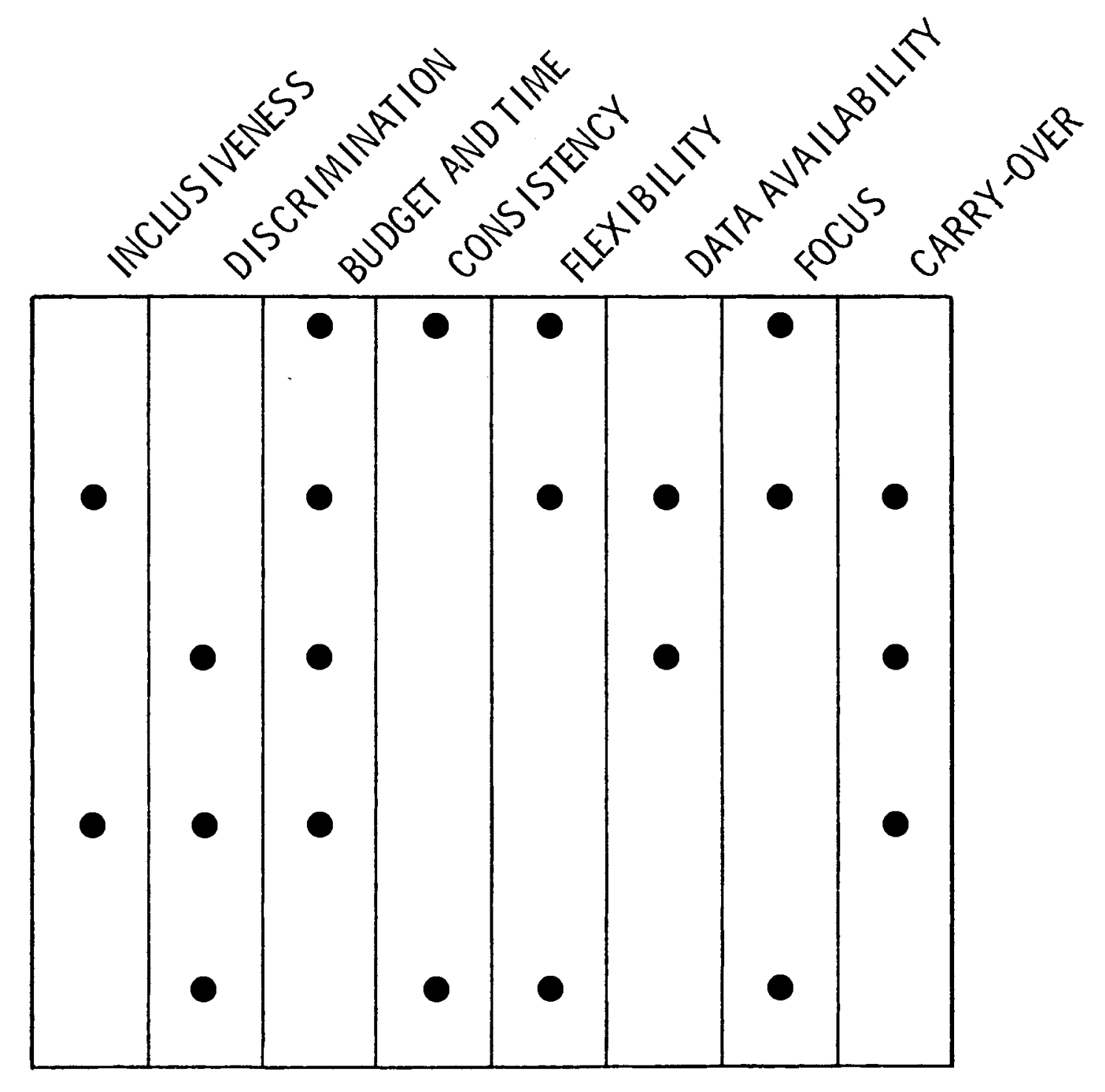

GROUPING OF FUEL CYCLES

IDENTIFICATION OF

E\&H ISSUES

EXPRESSION OF SOURCE TERMS

SPECIFICATION OF DEVELOPMENT SCENARIOS

COMPARISON OF FUEL CYCLES 
strategy is choosing among these grouping options. We recommend a "common process" approach be used to group fuel cycles. This approach identifies processes or fuel cycle stages in which several, or all, of the alternative nonproliferative fuel cycles under examination exhibit similar environmental impacts, differing principally only in the magnitude of these impacts. As an example, the following outline illustrates one possible common process organization:

Mining, milling, conversion, and enrichment

1. Uranium

2. Thorium

Fuel fabrication and reactor operation

3. Uranium fueled solid core reactors

4. Thorium fueled solid core reactors

5. Non-solid core (gaseous and liquid core) and other "exotic" reactors

Waste management

6. With reprocessing

7. Without reprocessing

Other feasible, but not recommended, assessment options include 1) conduct an independent assessment of each complete fuel cycle, and 2) classify all fuel cycles as either uranium- or thorium-related and conduct impact assessments on these two major groups. The independent assessment option would be simple and flexible in that two or more laboratories or groups of investigators could proceed with littie or no coordination required. The independent assessment option is not recommended, however, because it would not assure a consistent approach to assessment, allowing direct comparison of the environmental inpacts of fuel cycles and might not be achievable within time and budget constraints, due to the inefficiency resulting from separately examining many impacts expected to be similar for several fuel cycles. 
Assessing impacts by the two major fuel groups (uranium vs. thorium) is not recommended because at certain stages of the fuel cycles the differences in environmental impacts within these groups may exceed the differences between them.

The major benefits of the recommended common process approach are: 1) it would minimize redundancy; 2) it appears achievable within the expected time and budget constraints and 3) it would strongly focus on highlighting in a consistent manner the important environmental impacts of alternative fuel cycles. The common process approach is, however, somewhat more complex to coordinate since the impacts of a fuel cycle, identified through independent studies of three or more fuel cycle stages, would have to be combined to produce an overall assessment of the fuel cycle.

By breaking the assessments into analyses of stages rather than analyzing whole fuel cycles, the common process approach may provide an additional advantage over the other options. Assessment of complete cycles carries with it the danger that individual investigators or laboratories may come to identify some cycles as "theirs" with a resulting loss in objectivity, or may run the risk of exposing the NASAP effort to criticism on this basis. Since the assessments are expected to require application of considerable expert judgement, any option that might reduce objectivity should be avoided.

\subsubsection{Identification of Environmental and Health Issues}

The second major choice to be made in the development of an environmental assessment strategy is selection of the most appropriate environmental impacts to be examined. We recommend that a "key issues screen" approach be employed. This approach requires the identification of a small number (approximately 10) of potential environmental impacts that appear to be of sufficient importance to influence the selection of a preferred nonproliferative fuel cycle. This list of issues would be used to guide 
individual assessments. Not all the key issues would require treatment in detail in each assessment. Instead, the list of issues would serve as a screen or checklist for identifying the subset of environmental issues pertinent to any single assessment. Section 2, above, identifies candidate issues to be employed in such a key issues screen approach.

Alternative assessment options not recommended are 1) using a full range of all issues typically addressed in Environmental Impact Statements (EIS) as a screen, and 2) using only a smaller preselected set of key issues (perhaps 4-5) to be addressed in every assessment. The primary virtues of the full-range-EIS option are the high probability that no important environmental impacts will be overlocked, and the ease with which information collected in the NASAP assessments might be carried over to later impact statements. This approach is not recommended, however, because it would divert scarce time, budget, and manpower to address environmental impacts which, though real, would not be of sufficient magnitude or importance to influence the choice of a preferred fuel cycle. It is also doubtful that sufficient data will be available within the short time frame of the assessment work to address such a broad range of issues.

In contrast, the option of using a very small subset of issues to be addressed in each assessment has essentially opposite strengths and weaknesses. This option would result in a highly focused effort using time, money, and manpower efficiently. However, we are not confident that the 4-5 key issues can be identified at this time without a significant risk that potentially important concerns may be ignored. Section 2, above, for example, identifies several issues, the importance of which cannot be established in the absence of further information.

The recommended key issues screen option attempts to provide a workable middle ground, with concentration on major issues, but allowing the necessary flexibility to incorporate new information on questionable 
impacts. Section 2, above, provides a useful first cut at a key issues screen. We suggest, however, that further identification of key issues should be one of the first steps in further NASAP environmental assessment work.

Selection of a key issues screen approach for identifying environmental and health issues influences choices made in other categories of assessment options. It is more feasible to develop discrete or rangesof-values source term specifications (Section 3.3.3) for the more narrow list of issues, as compared to a full EIS analysis. The consistent use of a limited number of key issues also facilitates the direct comparison among fuel cycles (Section 3.3.5), although if not all key issues are addressed in each assessment, such comparisons will not be totally parallel, making ranking of fuel cycles difficult.

\subsubsection{Expression of Source Terms}

Source terms are defined as expressions of effluents and resource requirements for a particular technology per unit of output or input. They are not environmental impacts per se but represent inputs to transport models and other assessment techniques that ultimately estimate impacts on man and his environment. Several options are available for expressing these source terms. We recommend source terms be expressed as ranges of expected values. For each source term required, a range is estimated within which actual values are expected to fall, within specified confidence limits. For those source terms for which adequate data are available, the range will be narrow and perhaps a single most probable value can also be identified. Less well understood emissions would require a broader range of possible source term values.

Assessment options not recommended are: 1) single value expression of source terms, 2) expression of source terms by comparison to a reference cycle (e.g., LWR cycle), and 3) expression of terms by comparison with environmental standards. 
Single value best estimates of source terms are not recommended because we doubt that adequate data will be available within the study period to provide such estimates for all desired source terms. Specification of source terms as single values would, therefore, indicate false precision, masking actual uncertainties. The level of effort necessary to develop single value estimates, even if achievable within the time span of the assessment effort, also appears unjustified in the light of the lack of adequate transport models and other assessment tools for certain effluents, as discussed in a recent ORNL report (Meyer et al., 1977). Using ranges rather than single values leads to an apparent decrease in the ability of the resulting analyses to discriminate between the differing environmental impacts of alternative fuel cycles. This lack of discrimination would, however, be an accurate reflection of the state of present knowledge.

Specification of source terms by comparison with a well-known fuel cycle would result in source term descriptions such as "within one order of magnitude of the LWR level of effluent $X . "$ This approach, though perhaps simpler than either the single value or ranges-of-values options, would likely produce one of two equally undesirable results; either the analysis of impacts would become predominately qualitative and descriptive, or the comparative expressions would be translated into single value estimates, again suggesting a depth of knowledge we do not expect will be available within the study period.

Specification by comparison to standards would involve essentially qualitative statements that a particular effluent emission rate does or does not appear to exceed some generally accepted or recommended standard. Limited international standards, particularly for nonradiological effluents and for resource use, makes this option appear unworkable at this time. The resulting analysis would also be highly qualitative and descriptive and would make assessment of cumulative impacts from a worldwide full-scale industry difficult. 
The recommendation of ranges-of-values source term expressions influences our recommendation regarding the means of comparing fuel cycles in that it permits a quantitative, point-by-point comparison. Source term expression by comparison to a reference fuel cycle or to standards would probably necessitate a more descriptive approach to the final comparison of fuel cycle impacts.

\subsubsection{Specification of Development Scenarios}

The assessment of environmental impacts requires assumptions about the location, timing, and scale of development of a technology. An important aspect of developing a NASAP environmental assessment strategy is making these assumptions realistic and explicit, yet allowing comparability of impacts across fuel cycles. Because of the importance of international concerns in the selection of preferred fuel cycles, this section emphasizes options for specifying the locational aspects of development scenarios. Suggestions are also made, however, for dealing with time frame and scale aspects of development scenarios. These suggestions assume that a comparison of the cumulative international impacts of nuclear industries employing alternative fuel cycles is desired, in contrast to a comparison of single plants using alternative technologies.

We recommend that a development scenario be used which specifies one international distribution of facilities for uranium-based fuel cycles and a second distribution for thorium-based cycles. Such a development scenario would identify specific mining and reprocessingwaste management locations for each of these two major classes of fuel cycles. Common locations for reactor sites and other fuel cycle facilities might be used for all NASAP fuel cycle alternatives.

Assessment options not recommended are 1) specifying one common reference site for all facilities or all facilities of a certain type (e.g., mines, reactors, reprocessing plants, etc.); 2) specifying a 
single geographic distribution for facilities of all fuel cycles (reprocessing plants at sites $a, b$, and $c$, for example) and 3 ) providing no specific locational scenario, permitting unique development scenarios to be created during the course of individual assessments.

Use of a single common reference site, or a series of such sites for different fuel cycle stages, would result in failure of the resulting analyses to identify important differences between alternative fuel cycles in cumulative worldwide impacts and in the location of anticipated impacts. Though this assessment option would be simple to implement and would permit parallel assessment of aiternative cycles, it would also introduce distortions since any single site or set of sites would not be likely to fit the site needs of all fuel cycles.

An assessment option specifying a common geographic distribution of facilities would allow the analys is of cumulative impacts but would still not reflect the differing site needs of alternative fuel cycles. The recommended option (uranium cycle and thorium cycle distribution), in contrast, recognizes major differences in the mining, and perhaps waste management stages.

Choosing to identify no specific development scenario would seriously weaken the comparability of assessments of alternative fuel cycles since there would be no assurance the assumptions made in individual assessments were consistent.

Development scenarios should also define the time frame for environmental assessment and the scale of development to be anaiyzed. Failure to specify either factor will produce inconsistencies between assessments of alternative fuel cycles. One possible choice in specifying a time frame for analysis is to propose a "snapshot" analysis, assessing impacts occurring at some specific point in time--the year 2020, for example. A second choice of time frame would require an analysis of impacts occurring over some time period. This may be a fixed period (1980 to 2020, for example) or a variable period reflecting differences between alternative 
fuel cycles in their present state of development (the 40 years following commercialization of the technology, for example). We believe the specification of a time period would be the better choice for assessment of NASAP fuel cycles, because it would reveal cumulative resource use impacts and could take into account the differing rates of development expected for alternative fuel cycles.

In defining the scale of technology to be analyzed, there are four principal choices: 1) assessment on a per plant basis; 2) assessment of cumulative impacts of a specific number of plants, common to all fuel cycles; 3 ) assessment based on a total megawattage of annual worldwide energy production, and 4) assessment on the basis of the probable scale of each technology attainable by some target date. [If the target date selected under choice (4) is sufficiently distant, and full development of all alternative fuel cycles may be assumed, choices (3) and (4) merge.] We suggest the NASAP assessments specify some total annual megawattage to be produced by the end of a specified time period. This specification of scale would be compatible with the recommendations of a cumulative time frame and specified distribution of facilities for uranium vs. thorium based fuel cycles.

\subsubsection{Comparison of Fuel Cycles}

The final major category of options in developing an environmental assessment strategy for NASAP fuel cycles involves the format in which results are presented. In contrast to more typical environmental assessments contained in Environmental Impact Statements, we expect the NASAP assessments will be used principally to compare alternatives. Thus, assessment results must be highly consistent in treatment, emphasizing discrimination between fuel cycles. We recommend, therefore, that direct, point-by-point comparisons of fuel cycle impacts be made, without subjective ranking of fuel cycles. The comparisons we envision would include tables of findings for each fuel cycle for each of several relevant key environmental issues, accompanied by explanatory supporting text. Findings would be expressed quantitatively to the maximum extent possible. 
Other options not recommended are: 1) separate descriptive assessment reports for each fuel cycle, 2) comparisons with standards, and 3) direct comparisons among fuel cycles with a ranking of fuel cycles. Separate descriptive reports would obviously be a very flexible approach, requiring minimal coordination between assessments, but the failure of this approach to highlight contrasts between fuel cycles overweighs its simplicity. Comparison with standards would involve a point-by-point comparison of impacts of a fuel cycle against accepted or recommended standards. The comparison would probably be expressed in the form of "does or does not comply." Such an approach would be highly objective with clear-cut results. We do not recommend this choice, however, because of the lack of available standards for evaluating the full range of expected impacts (as discussed in Section 3.3.3, above), and because we doubt the method would discriminate adequately between alternative fuel cycles, since most cycles are expected to be able to meet existing (principally radiological) standards.

Direct comparisons among fuel cycles with ranking would, in contrast to the recommended approach, go beyond a largely objective point-bypoint expression of impacts to rank fuel cycles either on their overall environmental acceptability or on each key environmental issue analyzed. Obviously, results could be presented both with and without ranking to make clear and objective analyses underlying the more subjective rankings. Ranking is not recommended because of this subjectivity, and because of the difficulty of "weighting" impacts of various types to achieve an overall ranking. The "weighting" problem would be further complicated by the fact that it is probable not all key issues will be pertinent to all fuel cycles. We believe the time necessary to develop a defendable ranking would be more wisely spent in developing better objective estimates of impacts. Simpler, off-the-cuff rankings of fuel cycles can, and in any event undoubtedly will, be made by those synthesizing environmental findings with other issues in the overall selection of preferred fuel cycles. 


\subsection{Conclusions}

Sections 3.3.1 through 3.3.5 identify assessment options and recommend choices at five key points in the development of an environmental assessment strategy for the NASAP program. We believe the recommendations made are compatible, producing a logical and achievable assessment strategy. As has been emphasized at several points, the recommendations made are dependent on our assumptions that the assessment work will be limited by time, data availability, and financial constraints, and that an emphasis on contrasting fuel cycles is more important than comprehensiveness or definitiveness of the assessments. Other of the options presented may be preferable if imposed constraints vary. The recommendations made should, therefore, be regarded as preliminary only, and should be re-evaluated as the following questions are considered:

- What type of source term data will be available, and when will it become available?

- Which specific fuel cycles are to be analyzed?

- How much time and money will be available to conduct the analyses?

- What format for the E\&H analyses is desired to facilitate synthes is with other elements of the NASAP effort? 


\section{SUMMARY AND RECOMMENDATIONS}

The purpose of this report is to provide recommendations to DOE in developing an effective approach to the assessment of environmental and health (E\&H) impacts of alternative fuel cycles as part of the Nonproliferation Alternative Systems Assessment Program (NASAP). The report discusses $E \& H$ issues which could significantly influence the acceptability of a NASAP fuel cycle. It also identifies and evaluates strategy options that may be used in organizing the assessment efforts expected to be completed in Fy 1978.

\subsection{Key E\&H Issues}

The following concerns have been identified as potential key E\&H issues:

1. Occupational and public health risks associated with radioactive releases during mining and milling of uranium and thorium ores.

2. Occupational and public health risks associated with radioactive releases during conversion, enrichment and fuel fabrication.

3. Risks of contaminating the environment from radioactive releases during conversion, enrichment and fuel fabrication.

4. Risk of environmental degradation associated with thermal releases during enrichment operations.

5. Occupational and public health risks associated with radioactive releases during fuel reprocessing.

6. Risk of contaminating the environment with radioactive releases during fuel reprocessing.

7. Problems associated with meeting regulatory requirements for chemicals released from reprocessing operations.

8. Occupational and public health risks associated with wastes from reprocessing plants. 
9. Risk of contaminating the environment with radioactive releases from wastes generated at reprocessing plants.

10. Occupational and public health risks associated with the transportation of radioactive materials.

\subsection{Environmental Assessment Strategies}

We recommend the following environmental assessment strategy for analysis of the environmental impacts of alternative fuel cycles:

1. Fuel cycles are analyzed according to groups of common processes, exhibiting impacts similar in kind but perhaps different in magnitude.

2. Environmental concerns for analysis are identified by use of a screen or checklist of perhaps 10 key environmental issues.

3. Source terms are expressed as ranges of expected values.

4. A development scenario is used specifying approximate worldwide distributions of facilities for two major groups of fuel cycles, uranium- and thorium-based. This scenario whould also identify a specific time period to be considered, and should assume that all alternative technologies are producing a stated annual worldwide output of electrical energy by the end of the specified time period.

5. Direct point-by-point comparisons of alternative fuel cycles are made for each of the key environmental issues, without any additional ranking of cycles.

Issues identified and recommendations made should be considered as preliminary and subject to reconsideration as additional information on assessment scope becomes available and specific fuel cycles are selected for analysis. 


\section{REFERENCES}

Brenchley, D. L., J. K. Soldat, J. A. McNeese and E. C. Watson. 1977. Environmental Assessment Methodology for the Nuclear Fuel Cycle. BNWL-2219. Battelle, Pacific Northwest Laboratories, Richland, WA.

Clarke, R. H., H. F. MacDonald, J. Fitzpatrick and A. J. H. Goodard. 1975. Waste Disposal Aspects of the Long-term Cooling Characteristics of the Irradiated Nuclear Fuels. Ann Nucl Energy 2:451-466.

Finney, B. C., R. E. Blanco, R. C. Dahlman, G. S. Hill, F. G. Kitts, R. E. Moore, and J. P. Witherspoon. 1976. Correlation of Radioactive Waste Treatment Costs and the Environment Impact of Waste Effluents in the Nuclear Fuel Cycle: Reprocessing Light-Water Reactor Fuel. ORNL/ NUREG/TM-6. NTIS, Springfield, VA.

Killough, G. G. and L. R. McKay. 1976. A Methodology for Calculating Radiation Doses from Radioactivity Released to the Environment. ORNL4992, Oak Ridge National Laboratory, Oak Ridge, TN.

Meyer, H. R., et al. 1977. Nonprol iferation Alternative Systems Assessment Program (NASAP) - Prel iminary Environmental Assessment of Thorium/Uranium Fuel Cycle systems. ORNL/TM-6069 (in press), Oak Ridge National Laboratory, Oak Ridge, TN.

Pechin, W. H., R. E. Blanco, R. C. Dahlman, B. C. Finney, R. B. Lindauer, and J. P. Witherspoon. 1975. Correlation of Radioactive Waste Treatment Costs and the Environmental Impact of Waste Effluents in the Nuclear Fuel Cycle for Use in Establishing "as Low as Practicable" Guides: Fabrication of Light-Water Reactor Fuel from Enriched Uranium Dioxide. ORNL/TM-4902, NTIS, Springfield, VA. 
Roddy, J. W., R. E. Blanco, G. S. Hill, R. E. Moore, R. D. Seagren, and J. P. Witherspoon. 1976. Correlation of Radioactive Waste Treatment Costs and the Environmental Impact of Waste Effluents in the Nuclear Fuel Cycle: Fabrication of High-Temperature Gas-Cooled Reactor Fuel Containing Uranium-233 and Thorium. ORNL/NUREG/TM-5. NTIS, Springfield, VA.

Schneider, K. J., et al. 1977. Analys is of LWR Fuel Cycle Facilities. BNWL-2286. Batte1le, Pacific Northwest Laboratories, Richland, WA. (not cleared for public distribution)

U.S. Energy Research and Development Administration. 1976. Light-Water Breeder Reactor Program: Final Environmental Statement. ERDA-1541. NTIS, Springfield, VA.

U.S. Energy Research and Development Administration. 1977. Nonproliferation Alternative Systems Assessment Program - Prel iminary Program Plan. (Draft) Division of Nuclear Research and Applications, Nuclear Energy Assessments. 
No. of

Copies

\section{OFFSITE}

12 A. P. D'zmura

Division of Nuclear Research and Applications

Department of Energy

Germantown, MD 20767

12 B. W. Wachholz

Office of Environmental Policy Analys is

Department of Energy

Germantown, MD 20767

27 Oak Ridge National Laboratory

Oak Ridge, TN 37830
E. A. Bondietti
J. A. Carpenter, Jr.
W. Davis, Jr.
D. E. Dunning
C. T. Garten
F. 0. Hoffman
S. V. Kaye
C. A. Little (5)
H. R. Meyer (5)
R. E. Moore
P. S. Rohwer
J. E. Till (5)
C. C. Travis
P. J. Walsh
J. P. Witherspoon

No. of

Copies

ONSITE

1 DOE Richland Operations Office

H. Hansom

27 Battelle-Northwest

W. J. Bair (5)

J. E. Ballou

R. M. Emery (5)

W. I. Enderl in

R. F. Foster

J. C. Fox

T. R. Garland

D. L. Hessel

T. J. Kabele

S. Marks

W. L. Templeton

R. C. Thompson, Jr.

C. M. Unruh

B. E. Vaughan

M. L. Warner (5) 